\title{
What happens in the mantle?
}

\section{While it is generally agreed that continental drift occurs by the mechanisms of plate tectonics, the forces that drive these motions remain largely undescribed. But change may be on the way.}

AFTER more than 20 years of contentment bordering on complacency, the theory of plate tectonics seems in for a bout of disputation that may be as fierce (and as entertaining) as that of the late $1950 \mathrm{~s}$, when geophysics was divided into the two camps of neo-Wegenerians and the conservative rest. That the continents move relative to each other is not now substantially in dispute, of course: the reality of that phenomenon, originally inferred from observations of the deep oceanic crust, is now within the range of direct measurement using radio interferometry. The contentious question now is what drives continental drift? And what, in any case, goes on in the mantle on which the tectonic plates appear to float?

One small sign of which way the wind is blowing can be seen in the note by D.P. McKenzie on page 616 . Without saying as much, McKenzie deals with a point often raised by his Cambridge colleague, R.A. Lyttleton, in the past few years - how can the new orthodoxy account for the several recognized episodes of mountain-building in regions far distant from the places at which continents are colliding with each other, or where one plate is riding over another, as in the formation of the Himalayas and the Sierras?

On the standard view, the continents, with an average density of $2.8 \mathrm{~g} \mathrm{~cm}^{-3}$, float on the more dense mantle beneath in the particular sense to which geophysicists have made us familiar - adjustments take place on a timescale comparable with that of the plastic deformation of the solid material of the mantle. What McKenzie now says is that the mantle material beneath continents may differentiate into dense and less-dense components just as it does beneath the Earth's great spreading oceanic crust. But beneath the continents, the lighter material is either added to the basement or intruded at high levels as horizontal basalt slabs. In either case, the result is to make blocks of continental material more buoyant than they would otherwise have been. The result, the numbers suggest, may be some kilometres of uplift.

Orthodox geologists should be content. Mountain-building other than that provoked by the more spectacular tectonic events is made explicable. So too is the occurrence near the surface of metamorphic rocks, some even derived from sedimentary material, which have obviously in their time been deeply buried. This was precisely the phenomenon that
C.J. Allegre and his colleagues from the Institut de Physique du Globe in Paris were describing last month (Nature 307, 17; 1984). Whether this simple notion will settle the long-standing controversy about the origin of the Colorado plateau is less certain, given the great pleasure it gives to orthodox geologists.

Meanwhile, it may be thought puzzling that such a simple idea as McKenzie's has not been put forward long before this. The explanation seems to be that geophysicists have been unduly impressed with the apparent constancy of the thickness of the continental crust, almost everywhere within $5 \mathrm{~km}$ or so of $35 \mathrm{~km}$, and at the same time attracted by the simplicity of the notion that the continental crust is essentially primitive material which, once formed, remains on or near the surface. That some of it must do so is shown by the ages of the rocks of the ancient shield areas, exceeding 3,000 million years. But not everything is quite that simple.

Dr D.L. Anderson from the California Institute of Technology seems ready to make a more striking break with the new orthodoxy of plate tectonics (Science 223, 347 ; 1984). Starting from his own recent analysis of the speeds of seismic waves in the upper reaches of the Earth's mantle, Anderson outlines a framework within which the entire standard model of what happens in the mantle might be recast. The observations show that seismic speeds vary from one place to another, as gravity anomalies are known to do, while there is the now long-standing expectation that the regions of continental crust will act as an insulating blanket for the mantle beneath, where the temperature should as a consequence be greater than that elsewhere. Briefly, low seismic velocities signal relatively high temperatures.

Part of Anderson's argument is that these lateral temperature gradients must have an important influence on what happens within the mantle. Few will dissent from that. So what happens to the standard view of what happens in the mantle and of what drives continental drift - the notion that the mantle is one huge pattern of thermal convection cells in which hot material rises (along the lines marked out by the spreading centre) and sinks as cold material where the edges of oceanic plates re-enter the Earth by the process called subduction at the continental margins (southeast Pacific) and at island arcs (western Pacific)?
The remarkable feature of this convection process is that it has been so vague. If the present disposition of the continents and of the plates on which they are mounted is simply to be explained by a pattern of convection cells, at least some features of that pattern must have persisted for some 180 million years, the age of the oldest rocks so far found in the oceanic crust (in the south-east Pacific). So one would expect that the outlines of these convection cells would by now have been fully described, and the outlines of their ascending and descending walls drawn out on maps as befits important influences on the surface structure of the Earth. Then, by comparison with some theory of convection, it should be possible to tell what fraction of the driving force is represented by the thermal energy of the Earth's interior and how much by other influences. But in reality, even the depth of the supposed convection cells has been uncertain, although the discontinuity of seismic velocities at $670 \mathrm{~km}$ has been most people's favourite candidate.

Anderson's view of the upper reaches of the mantle is radically different. First, he says, it is not even vertically homogeneous but, rather, layered, as would be expected for a large body of material that has undergone continual zone-refining over aeons. The zone-refining consists of the liberation from the deeper rocks of those components which form liquids, or which can melt, and, on the same view, the buoyancy of the molten material is what drives upward convection. The apparent discontinuity of $670 \mathrm{~km}$ is not a phase transition within chemically homogeneous material but a region where both chemical composition and physical properties are changing.

If this way of describing what happens in the mantle proves correct, the consequences will be interesting. First, mantle convection need not be a continuous process but may be episodic indeed, Anderson argues that the fragmentation of Gondwanaland may be most simply understood as the consequence of the accumulation of heat beneath it, setting off the instability that has continued ever since. And - this is the real radicalism the occurrence of positive gravity anomalies may not be accidental but, instead, a sign that one consequence of mantle activity is that the Earth's moments of inertia can be changed so as to reorient the mantle as a whole with respect to the spin axis of the Earth. John Maddox 